\title{
Intraoperative Ultrasonographic Assessment of Vocal Cord motion following pediatric thyroidectomy in the Era of COVID-19, a double-blind study
}

\author{
Ofir Zavdy ${ }^{1}$, Michael Schwarz ${ }^{2}$, Dror Gilony ${ }^{1}$, Gideon Bachar ${ }^{1}$, Hanna Gilat ${ }^{1}$, and Roy \\ $\operatorname{Hod}^{1}$ \\ ${ }^{1}$ Rabin Medical Center \\ ${ }^{2}$ Schneider Children's Medical Center of Israel
}

April 3, 2021

\begin{abstract}
Unilateral vocal cord paralysis (UVCP) is a known complication of thyroid surgery, due to iatrogenic recurrent laryngeal nerve injury, with reported rates of $2-5 \%$ in children. The gold standard for assessing vocal cord function in flexible nasendoscopy (FNE) examination, which is considered high-risk for contraction of the COVID-19 virus. Intraoperative ultrasonographic assessment (IUA) of vocal cord function is a non-invasive and relatively simple procedure, performed in a supine position under general anesthesia. Objectives: To evaluate the validity of IUA modality in children undergoing thyroidectomy, and to compare it to the standard FNE. Design: A prospective double-blind study covering 24 months (March 2019-March 2021). Twenty thyroid lobectomies were performed, during 15 surgeries. Vocal cord function was assessed three times: Preoperatively by FNE, intraoperative (IUA) following extubation, and a second FNE on the first post-operative day. Settings: A tertiary pediatric hospital. Results: The overall accuracy of IUA results in our study was $92 \%$. IUA sensitivity, specificity, positive and negative predictive values were $100 \%, 89 \%, 33 \%$, and $100 \%$ respectively. Patient's age demonstrated borderline significance ( $\mathrm{p}=0.08)$. The resident's experience was associated with a better correlation between IUA and FNE results $(\mathrm{p}<0.05)$. Conclusions: IUA of vocal cord motion has a high accuracy rate for detection of iatrogenic vocal cord paralysis, similar to FNE. It is easily learned by residents, well tolerated by children, and it provides a safe and valid alternative modality while ensuring the safety of the medical staff in treating patients, especially in times of COVID-19 pandemic.
\end{abstract}

\section{Hosted file}

Main document.pdf available at https://authorea.com/users/400020/articles/516546intraoperative-ultrasonographic-assessment-of-vocal-cord-motion-following-pediatricthyroidectomy-in-the-era-of-covid-19-a-double-blind-study 


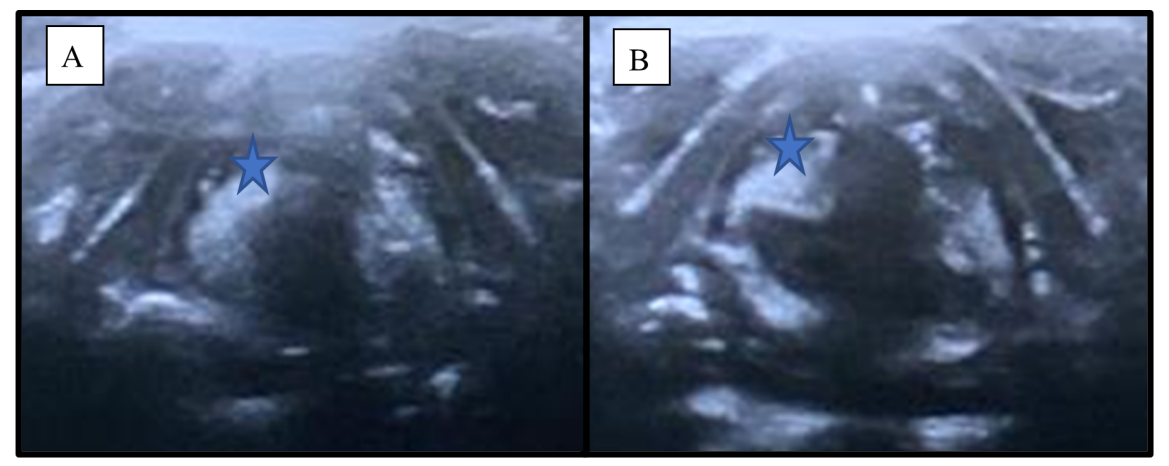

\section{Hosted file}

Tables.pdf available at https://authorea.com/users/400020/articles/516546-intraoperativeultrasonographic-assessment-of-vocal-cord-motion-following-pediatric-thyroidectomy-inthe-era-of-covid-19-a-double-blind-study 